\title{
Preclinical evaluation of carbon-11 and fluorine- 18 sulfonamide derivatives for in vivo radiolabeling of erythrocytes
}

Olivier Gheysens ${ }^{1,2+}$, Vamsidhar Akurathi ${ }^{3 \dagger}$, Rufael Chekol ${ }^{3}$, Tom Dresselaers ${ }^{4}$, Sofie Celen ${ }^{3}$, Michel Koole ${ }^{1,2}$, Dieter Dauwe ${ }^{5,6}$, Bernard J Cleynhens ${ }^{3}$, Piet Claus ${ }^{7}$, Stefan Janssens ${ }^{5,6}$, Alfons M Verbruggen ${ }^{3}$, Johan Nuyts ${ }^{1,2}$, Uwe Himmelreich $^{4}$ and Guy M Bormans ${ }^{3^{*}}$

\begin{abstract}
Background: To date, few PET tracers for in vivo labeling of red blood cells (RBCs) are available. In this study, we report the radiosynthesis and in vitro and in vivo evaluation of ${ }^{11} \mathrm{C}$ and ${ }^{18} \mathrm{~F}$ sulfonamide derivatives targeting carbonic anhydrase II (CA II), a metallo-enzyme expressed in RBCs, as potential blood pool tracers. A proof-of-concept in vivo imaging study was performed to demonstrate the feasibility to assess cardiac function and volumes using electrocardiogram (ECG)-gated positron emission tomography (PET) acquisition in comparison with cine magnetic resonance imaging (CMRI) in rats and a pig model of myocardial infarction.

Methods: The inhibition constants $\left(K_{\mathrm{i}}\right)$ of CA II were determined in vitro for the different compounds by assaying CA-catalyzed $\mathrm{CO}_{2}$ hydration activity. Binding to human RBCs was estimated after in vitro incubation of the compounds with whole blood. Biodistribution studies were performed to evaluate tracer kinetics in NMRI mice. ECG-gated PET acquisition was performed in Wistar rats at rest and during pharmacological stress by infusing dobutamine at $10 \mu \mathrm{g} / \mathrm{kg} / \mathrm{min}$ and in a pig model of myocardial infarction. Left ventricular ejection fraction (LVEF) and volumes were compared with values from cMRI.

Results: The $K_{\mathrm{i}}$ of the investigated compounds for human CA II was found to be in the range of 8 to $422 \mathrm{nM}$. The fraction of radioactivity associated with RBCs was found to be $\geq 90 \%$ at 10- and 60-min incubation of tracers with heparinized human blood at room temperature for all tracers studied. Biodistribution studies in mice indicated that $30 \%$ to $67 \%$ of the injected dose was retained in the blood pool at 60 min post injection. A rapid and sustained tracer uptake in the heart region with an average standardized uptake value of 2.5 was observed from micro-PET images. The LVEF values obtained after pharmacological stress in rats closely matched between the CMRI and micro-PET values, whereas at rest, a larger variation between LVEF values obtained by both techniques was observed. In the pig model, a good agreement was observed between PET and MRI for quantification of left ventricular volumes and ejection fraction.
\end{abstract}

Conclusions: The ${ }^{11} \mathrm{C}$ and ${ }^{18} \mathrm{~F}$ sulfonamide derivatives can be used for efficient in vivo radiolabeling of RBCs, and proof-of-concept in vivo imaging studies have shown the feasibility and potential of these novel tracers to assess cardiac function.

Keywords: Blood pool imaging, Carbonic anhydrases, PET tracers, Sulfonamides

\footnotetext{
*Correspondence: guy.bormans@pharm.kuleuven.be

†Equal contributors

${ }^{3}$ Laboratory of Radiopharmacy, Katholieke Universiteit Leuven, O\&N2,

Herestraat 49, Box 821, Leuven BE-3000, Belgium

Full list of author information is available at the end of the article
}

\section{国 Springer}

(c) 2013 Gheysens et al.; licensee Springer. This is an Open Access article distributed under the terms of the Creative Commons Attribution License (http://creativecommons.org/licenses/by/2.0), which permits unrestricted use, distribution, and reproduction in any medium, provided the original work is properly cited. 


\section{Background}

Radiolabeled red blood cells (RBCs) are used in the assessment of blood pool dynamics, for investigating angiofibroma and gastrointestinal hemorrhage and for localizing intramuscular hemangioma [1-5]. To date, very few positron emission tomography (PET) tracers have been reported as RBC labeling agents. ${ }^{68} \mathrm{Ga}$-oxine has been used for the labeling of RBCs, but this requires an in vitro labeling procedure [6]. Examples of agents for in vivo $\mathrm{RBC}$ labeling are ${ }^{11} \mathrm{CO}$ and $\mathrm{C}^{15} \mathrm{O}$ in gaseous form [7-9]. Due to in vivo instability and as a requirement of the sophisticated equipment for inhalation of these tracer gases, extensive usage of these tracers in preclinical or clinical studies is limited. Recently, human serum albumin (HSA) and rat serum albumin (RSA) were labeled with ${ }^{62} \mathrm{Cu}$ and ${ }^{68} \mathrm{Ga}$, but one of the limitations with ${ }^{62} \mathrm{Cu}$ is the in vivo instability of the complex, and ${ }^{68} \mathrm{Ga}-\mathrm{DOTA}$-HSA has yet to prove its clinical application [10-12].

Radiolabeling of rat and human RBCs by specific enzyme-inhibitor approach was first reported in 1991 by Singh et al. with ${ }^{123} \mathrm{I}$ - or ${ }^{125} \mathrm{I}$-labeled $p$-iodobenzenesulfonamide targeting carbonic anhydrase I and II (CA I and II), a metalloenzyme found in RBCs [13,14]. The authors found that the activity associated with RBCs decreased to about $50 \%$ of the injected dose (ID) at $24 \mathrm{~h}$ post injection (p.i.) in rats, whereas more than $88 \%$ of the ID remained associated with RBCs at $24 \mathrm{~h}$ p.i. in human volunteers. Fluorine-18 has appealing characteristics as a radionuclide for PET as large batches $(>500 \mathrm{GBq})$ of fluorine-18 can be produced by current cyclotrons, and the half-life of $110 \mathrm{~min}$ allows distribution from the production site to multiple remote PET sites.

The short half-life of carbon- 11 precludes its distribution but results in lower radiation burden to the patient and allows the combination of scans with different PET tracers in a 1-day protocol.

In this study, we report the evaluation of ${ }^{11} \mathrm{C}$ - and ${ }^{18} \mathrm{~F}$ labeled sulfonamides for in vitro and in vivo labeling of RBCs. In addition, a proof-of-concept in vivo imaging study was carried out with 4 - $\left(2-\left[{ }^{18} \mathrm{~F}\right]\right.$ fluoroethoxy)benzenesulfonamide, $\left[{ }^{18} \mathrm{~F}\right]-(5)$, to assess the feasibility to calculate left ventricular (LV) volumes and ejection fraction $(E F)$ in comparison with cine magnetic resonance imaging (cMRI). Currently, LV function and volumes are most commonly assessed by conventional equilibriumgated radionuclide angiography and echocardiography. The latter is a widely available technique with easy access but is limited by a high inter- and intra-observer variability and compromised echogenicity in obese patients. More recently, the cMRI technique is more widely used in clinical routine to estimate left ventricular ejection fraction (LVEF) values and heart function, especially in patients with dilated or distorted ventricles, due to its high-resolution functional images. Echocardiography and MRI are based on several assumptions of LV geometry which may not hold true in dysfunctional LV in contrast with radionuclide-based techniques that are less dependent on geometrical assumptions. In addition, for patients with pacemakers, defibrillators, or other implanted electronic devices that preclude cMRI, PET imaging offers a valuable alternative for cMRI. Therefore, PET blood pool agents that have a potential to assess cardiac function are an added value in nuclear cardiology.

\section{Methods}

\section{Chemistry and radiochemistry}

In detail description of synthesis of precursors, reference analogs ( 1 to 5$)$ and production of the secondary radiolabeling agents ${ }^{11} \mathrm{CH}_{3} \mathrm{I}$ and ${ }^{18} \mathrm{FEtBr}$ are summarized in Additional file 1.

\section{4- $\left(2-\left[{ }^{18} F\right]\right.$ fluoroethoxy)benzoyl}

aminoethylbenzenesulfonamide $\left[{ }^{18} \mathrm{~F}\right]-(3)$ and $4-\left[{ }^{11} \mathrm{C}\right]$ methoxybenzoyl aminoethylbenzenesulfonamide $\left[{ }^{11} \mathrm{C}\right]-(4)$

The synthons ${ }^{11} \mathrm{CH}_{3} \mathrm{I}$ or ${ }^{18} \mathrm{FEtBr}$ were bubbled into a solution consisting of the phenolic precursor, 4-hydroxy$\mathrm{N}$-[2-(4-sulfamoylphenyl)ethyl]benzamide $\quad\left(\begin{array}{llll}2 & 0.2 & \mathrm{mg}\end{array}\right)$ and $\mathrm{Cs}_{2} \mathrm{CO}_{3}$ (1 to $2 \mathrm{mg}$ ) in anhydrous dimethylformamide (DMF). The reaction mixture was heated at $90^{\circ} \mathrm{C}$ for $5 \mathrm{~min}\left({ }^{11} \mathrm{CH}_{3} \mathrm{I}\right)$ or $15 \mathrm{~min}\left({ }^{18} \mathrm{FEtBr}\right)$. The reaction mixture was diluted with water $(1 \mathrm{~mL})$ and injected onto a high-performance liquid chromatography (HPLC) system (XBridge $\mathrm{C}_{18}$ column, $5 \mu \mathrm{m}, 4.6 \times 150 \mathrm{~mm}$; Waters Corporation, Milford, MA, USA) eluted with a mixture of $0.05 \mathrm{M} \mathrm{NaOAc}(\mathrm{pH} 5.5)$ and $\mathrm{EtOH}(80: 20 v / v)$ at a flow rate of $1 \mathrm{~mL} / \mathrm{min}$. UV detection of the HPLC eluate was performed at $254 \mathrm{~nm}$. The radiolabeled product $\left[{ }^{18} \mathrm{~F}\right]-(3)$ was collected after $15 \mathrm{~min}$ and $\left[{ }^{11} \mathrm{C}\right]-(4)$ eluted $11 \mathrm{~min}$ after injection on the HPLC system. The collected peak corresponding to the desired radioligand was then diluted with saline (Mini Plasco ${ }^{\circledR}$, Braun, Melsungen, Germany) to obtain a final EtOH concentration of $\leq 5 \%$, and the solution was filtered through a sterile $0.22-\mu \mathrm{m}$ membrane filter $\left(\right.$ Millex $^{\circledR}-\mathrm{GV}$, Millipore Co., Billerica, MA, USA). Quality control was performed on an analytical HPLC system consisting of an XBridge $\mathrm{C}_{18}$ column $(3.5 \mu \mathrm{m}, 3 \times 100 \mathrm{~mm}$; Waters Corporation) eluted with a mixture of $0.05 \mathrm{M} \mathrm{NaOAc}$ buffer (pH 5.5) and acetonitrile $(80: 20 \mathrm{v} / \mathrm{v})$ at a flow rate of $0.8 \mathrm{~mL} / \mathrm{min}$. UV detection was performed at $254 \mathrm{~nm}$. The tracers $\left[{ }^{18} \mathrm{~F}\right]-(3)$ and $\left[{ }^{11} \mathrm{C}\right]-(\mathbf{4})$ were eluted at 10 and $5 \mathrm{~min}$, respectively, and their identity was confirmed by co-elution with authentic nonradioactive reference solutions. The tracers $\left[{ }^{18} \mathrm{~F}\right]-(3)$ and $\left[{ }^{11} \mathrm{C}\right]-(4)$ were synthesized with a decay-corrected radiochemical yield of $45 \%$ and $30 \%(n=3)$, respectively (relative to the starting radioactivity of ${ }^{18} \mathrm{FEtBr}$ and ${ }^{11} \mathrm{CH}_{3} \mathrm{I}$ ), 
and with a radiochemical purity of $\geq 98 \%$. Starting from ${ }^{18} \mathrm{FEtBr}$ and ${ }^{11} \mathrm{CH}_{3} \mathrm{I}$, the synthesis time to obtain the pure product was $50 \pm 10 \mathrm{~min}$ for $\left[{ }^{18} \mathrm{~F}\right]-(3)$ and $40 \pm 5 \mathrm{~min}$ for $\left[{ }^{11} \mathrm{C}\right]-(4)$. The average specific activity was found to be in the range of 37 to $71 \mathrm{GBq} / \mu \mathrm{mol}$ at the end of synthesis (EOS).

\section{4-(2- $\left[{ }^{18} \mathrm{~F}\right]$ fluoroethoxy)benzenesulfonamide $\left[{ }^{18} \mathrm{~F}\right]-(5)$ and 4- $\left[{ }^{11} \mathrm{C}\right]$ methoxybenzene sulfonamide $\left[{ }^{11} \mathrm{C}\right]-(6)$}

The synthons ${ }^{18} \mathrm{FEtBr}$ or ${ }^{11} \mathrm{CH}_{3} \mathrm{I}$ were bubbled into a solution of the phenolic precursor 4-hydroxybenzene1-sulfonamide $(0.8 \mathrm{mg})$ in a mixture of $1 \mathrm{M} \mathrm{NaOH}$ $(2.5 \mu \mathrm{L})$ and DMF $(0.3 \mathrm{~mL})$. The mixture was heated at $90^{\circ} \mathrm{C}$ for $5 \mathrm{~min}\left({ }^{11} \mathrm{CH}_{3} \mathrm{I}\right)$ or $15 \mathrm{~min}\left({ }^{18} \mathrm{FEtBr}\right)$. The crude mixture was diluted with water $(1 \mathrm{~mL})$ and injected onto an HPLC column (XTerra $\mathrm{C}_{18}, 5 \mu \mathrm{m}, 7.8 \times 150 \mathrm{~mm}$; Waters Corporation) eluted with a mixture of $0.05 \mathrm{M}$ $\mathrm{NH}_{4} \mathrm{OAc}(\mathrm{pH} 6.8)$ and $\mathrm{EtOH}(90: 10 v / v)$ at a flow rate of $2 \mathrm{~mL} / \mathrm{min}$. UV detection of the HPLC eluate was performed at $254 \mathrm{~nm}$. The radiolabeled product $\left[{ }^{18} \mathrm{~F}\right]-(5)$ was collected after $16 \mathrm{~min}$, and $\left[{ }^{11} \mathrm{C}\right]-(\mathbf{6})$ was eluted after 15 min on the HPLC system. The collected peak corresponding to the desired radioligand was then diluted with saline (Mini Plasco ${ }^{\circledR}$, Braun, Melsungen, Germany) to obtain a final EtOH concentration of $\leq 5 \%$, and the solution was sterile filtered through a $0.22-\mu \mathrm{m}$ membrane filter (Millex ${ }^{\circledR}-\mathrm{GV}$, Millipore Co.). QC was performed on an analytical HPLC system consisting of an XTerra $\mathrm{C}_{18}$ column $(5 \mu \mathrm{m}, 4.6 \times 250 \mathrm{~mm}$; Waters Corporation). For $\left[{ }^{18} \mathrm{~F}\right]-(5)$, the mobile phase was a mixture of $0.05 \mathrm{M}$ $\mathrm{NH}_{4} \mathrm{OAc}(\mathrm{pH} 6.8)$ and EtOH $(80: 20 v / v)$; for $\left[{ }^{11} \mathrm{C}\right]-(\mathbf{6})$, a mixture of $0.05 \mathrm{M} \mathrm{NH}_{4} \mathrm{OAc}(\mathrm{pH} 6.8)$ and acetonitrile $(80: 20 \mathrm{v} / \mathrm{v})$ was used. The flow rate was $0.9 \mathrm{~mL} / \mathrm{min}$. UV detection was performed at $254 \mathrm{~nm}$. The tracers $\left[{ }^{18} \mathrm{~F}\right]-(5)$ and $\left[{ }^{11} \mathrm{C}\right]-(6)$ were eluted at 11 and $9 \mathrm{~min}$, respectively, and the identity of the tracers was confirmed by coelution with authentic nonradioactive reference solutions. The tracers $\left[{ }^{18} \mathrm{~F}\right]-(5)$ and $\left[{ }^{11} \mathrm{C}\right]-(\mathbf{6})$ were synthesized with a decay-corrected radiochemical yield of $65 \%(n=3)$ and with a radiochemical purity of $\geq 98 \%$. Starting from ${ }^{18} \mathrm{FEtBr}$ and ${ }^{11} \mathrm{CH}_{3} \mathrm{I}$, the synthesis time to obtain the pure product was $55 \pm 10 \mathrm{~min}$ for $\left[{ }^{18} \mathrm{~F}\right]-(5)$ and $50 \pm 5 \mathrm{~min}$ for $\left[{ }^{11} \mathrm{C}\right]-(6)$. The average specific activity for both tracers was found to be $90 \mathrm{GBq} / \mu \mathrm{mol}$ at the EOS.

\section{In vitro studies}

\section{Log D (1-octanol/phosphate buffer $\mathrm{pH} 7.4)$}

Determination of the distribution coefficient $\left(\log \mathrm{D}_{1 \text {-octa- }}\right.$ nol/phosphate buffer $\mathrm{pH}$ 7.4), was carried out by a shake flask method [15]. An aliquot $(25 \mu \mathrm{L})$ of the tracer agents $\left[{ }^{18} \mathrm{~F}\right]-(3),\left[{ }^{11} \mathrm{C}\right]-(4),\left[{ }^{18} \mathrm{~F}\right]-(5)$, or $\left[{ }^{11} \mathrm{C}\right]-(6)$ (185 to 555 $\mathrm{kBq} / \mathrm{mL})$ was added to a polypropylene tube $(5 \mathrm{~mL}$; Sarstedt, Nümbrecht, Germany) containing $2 \mathrm{~mL}$ of $0.025 \mathrm{M}$ sodium phosphate buffer $\mathrm{pH} 7.4$ and $2 \mathrm{~mL}$ of 1-octanol. The tube was vortexed for $2 \mathrm{~min}$ at room temperature followed by centrifugation at 3,000 rpm for 10 min (Eppendorf centrifuge 5810, Eppendorf, Westbury, NY, USA). Aliquots of $50 \mu \mathrm{L}$ of the 1-octanol phase and $500 \mu \mathrm{L}$ of the phosphate buffer phase were pipetted into separate tared Eppendorf tubes with adequate care to avoid cross contamination between the two phases. The samples were weighed, and radioactivity was quantified using an automated gamma counter. The experiments were carried out sixfold.

\section{Determination of inhibition constant}

The inhibition constants $\left(K_{\mathrm{i}}\right)$ of the reference analogs (3), (4), (5), and (6) against human CA (hCA) I and II isozymes were determined by assaying the CA-catalyzed $\mathrm{CO}_{2}$ hydration activity [16], using Applied Photophysics' (Leatherhead, UK) stopped-flow instrument. Phenol red $(0.2 \mathrm{mM})$ was used as indicator, working at the absorbance maximum of $557 \mathrm{~nm}$, with $10 \mathrm{mM}$ Hepes as buffer ( $\mathrm{pH} 7.5$ ) and $0.1 \mathrm{M} \mathrm{Na}_{2} \mathrm{SO}_{4}$ (for maintaining constant ionic strength) at $25^{\circ} \mathrm{C}$ following the $\mathrm{CA}$-catalyzed $\mathrm{CO}_{2}$ hydration reaction for a period of 10 to $100 \mathrm{~s}$ (the uncatalyzed reaction needs around 60 to $100 \mathrm{~s}$ under assay conditions, whereas the catalyzed reactions take around 6 to $10 \mathrm{~s}$ ). The $\mathrm{CO}_{2}$ concentrations ranged from 1.7 to $17 \mathrm{mM}$ for the determination of kinetic parameters. Each compound was tested in the concentration range between $0.01 \mathrm{nM}$ to $100 \mu \mathrm{M}$. The uncatalyzed rates were determined in the same manner and subtracted from the total observed rates. Stock solutions of the compounds $(0.1 \mathrm{mM})$ were prepared in distilled water with $10 \%$ to 20\% $(v / v)$ DMSO (which is non-inhibitory at these concentrations), and dilutions up to $0.01 \mathrm{nM}$ were made with distilled water. Inhibitor and enzyme solutions were preincubated together for $15 \mathrm{~min}$ at room temperature prior to the assay, in order to allow the formation of enzyme-inhibitor complex. The inhibition constants were obtained by nonlinear least square methods using PRISM 3 (GraphPad Software, La Jolla, CA, USA), and they represent the mean from at least three different determinations.

\section{Whole blood analysis}

Blood samples from a healthy human volunteer were collected in a BD vacutainer ${ }^{\mathrm{TM}}(4.5 \mathrm{~mL}$; containing lithium heparin; BD, Franklin Lakes, NJ, USA). Aliquots of whole blood $(0.4 \mathrm{~mL})$ were incubated with $\left[{ }^{11} \mathrm{C}\right]-(4)$ or $\left[{ }^{11} \mathrm{C}\right]-(6)(370 \mathrm{kBq} / 0.1 \mathrm{~mL})$ for $10 \mathrm{~min}$ and with $\left[{ }^{18} \mathrm{~F}\right]-(3)$ or $\left[{ }^{18} \mathrm{~F}\right]-(5) \quad(37 \mathrm{kBq} / 0.1 \mathrm{~mL})$ for $60 \mathrm{~min}$ at room temperature. A different incubation time with ${ }^{11} \mathrm{C}$ and ${ }^{18} \mathrm{~F}$ tracer agents was used considering the radionuclides' half-life $\left({ }^{11} \mathrm{C}, 20 \mathrm{~min} ;{ }^{18} \mathrm{~F}, 110 \mathrm{~min}\right)$. After incubation for 10 or $60 \mathrm{~min}$, the plasma was separated from the blood cells by centrifugation at $3,000 \mathrm{rpm}(1,837 \times g)$ for $5 \mathrm{~min}$ 
(Eppendorf centrifuge 5810). To remove residual plasma and unbound tracer from the RBCs, phosphate-buffered saline (PBS) $\mathrm{pH}$ 7.4 $(0.4 \mathrm{~mL})$ was added to the cell fraction. After incubation for $2 \mathrm{~min}$, the PBS was separated from the RBCs using centrifugation. This rinsing procedure was carried out twice. For competition studies with acetazolamide (AAZ), the same procedure was followed as mentioned afore. To the whole blood and tracer agent mixture, a solution of AAZ $(0.1 \mathrm{~mL})$ was added to result final concentrations of $0.01,0.1,0.2,0.3$, $0.4,0.5$, and $1.0 \mathrm{mM}$, and as a control, PBS $(0.1 \mathrm{~mL}$, PBS $\mathrm{pH}$ 7.4) was added. The radioactivity associated with the RBCs and plasma was quantified using an automated gamma counter.

\section{Distribution of activity within the blood}

Human blood $(12 \mathrm{~mL})$ was collected in a syringe containing 2.4 $\mathrm{mL} \mathrm{ACD}$ (citrate-dextrose solution), and 3.7 $\mathrm{MBq}$ was added and gently mixed. Two milliliters of a $2 \%$ methylcellulose was added, gently mixed, and allowed to stand for $60 \mathrm{~min}$ so that the RBCs sediment by gravity. The supernatant was carefully drawn and centrifuged at $1,000 \mathrm{rpm}(140 \times \mathrm{g})$ for $5 \mathrm{~min}$. The plasmarich supernatant and white blood cell (WBC)-rich pellet were separated [17]. The activity in the three fractions was counted using an automated gamma counter. The procedure was carried out in triplicate.

\section{In vivo studies}

\section{Biodistribution studies}

The biodistribution studies were performed in wild-type NMRI mice with body weights ranging from 30 to $40 \mathrm{~g}$. Mice were intravenously injected with $0.1 \mathrm{MBq}$ of $\left[{ }^{18} \mathrm{~F}\right]$ (3) or $\left[{ }^{18} \mathrm{~F}\right]-(5)$ and $5.5 \mathrm{MBq}$ of $\left[{ }^{11} \mathrm{C}\right]-(4)$ or $\left[{ }^{11} \mathrm{C}\right]-(6)$ under anesthesia (2\% isoflurane in $\mathrm{O}_{2}$ at a flow rate of 1 $\mathrm{L} / \mathrm{min})$. The animals were killed by decapitation at 2 $\min$ or $60 \mathrm{~min}$ p.i. $\left(n=4 /\right.$ time point for $\left[{ }^{18} \mathrm{~F}\right]-(3)$, $\left[{ }^{11} \mathrm{C}\right]-$ (4), and $\left[{ }^{11} \mathrm{C}\right]-(6) ; n=6$ for $\left.\left[{ }^{18} \mathrm{~F}\right]-(5)\right)$. Blood was collected, and all major organs were dissected and collected in tarred tubes and were weighed. The radioactivity in each organ was counted using an automated gamma counter, corrected for background radioactivity and expressed as follows: percentage of the injected dose (\% ID) or as standardized uptake value (SUV) $($ SUV = (Counts in tissue per gram of tissue) / (Injected counts per total body mass (g)). For the calculation of total radioactivity in the blood, blood mass was assumed to be $7 \%$ of the body mass [18].

\section{Small animal imaging studies}

PET images were acquired on a FOCUS 220 tomograph (Siemens/Concorde Microsystems, Knoxville, TN, USA). During all scan sessions, rats were anesthetized $(2.5 \%$ isoflurane in $\mathrm{O}_{2}$ at a flow rate of $1 \mathrm{~L} / \mathrm{min}$ ) and scanned in prone position. $\left[{ }^{18} \mathrm{~F}\right]-(5)(37 \mathrm{MBq})$ was administered via the tail vein, and a 1-h dynamic scan was acquired. The images were acquired in list mode and binned in sinograms using a 21-dynamic frame protocol $(4 \times 15,4 \times$ $60,5 \times 180,8 \times 300 \mathrm{~s}$ ). Reconstruction was performed with the Focus 220 software (using Fourier rebinning, followed by two-dimensional (2D) OSEM algorithm), and data were analyzed using PMOD (version 2.65; PMOD, Zurich, Switzerland). The radioactivity concentration in the heart region was expressed as SUVs as a function of time after injection of the radiotracer.

An electrocardiogram (ECG)-gated micro-PET scan was performed with anesthetized (2.5\% isoflurane in $\mathrm{O}_{2}$ at a flow rate of $1 \mathrm{~L} / \mathrm{min})$ Wistar rats $(n=2)$ after administration of $48 \mathrm{MBq} / 0.7 \mathrm{~mL}$ of $\left[{ }^{18} \mathrm{~F}\right]-(5)$ via the tail vein. The acquisition was carried out at rest $(0.5 \mathrm{~h})$ and stress $(0.5 \mathrm{~h})$ by infusion of dobutamine at $10 \mu \mathrm{g} / \mathrm{kg} / \mathrm{min}$. The acquired data were reconstructed into a series of 12 ECG-gated images. To reduce noise, images were filtered with a 3D Gaussian filter (FWHM $1 \mathrm{~mm}$ ) along the spatial dimensions and with a low pass filter (preserving only the mean and the first four harmonics) along the time dimension. A volume of interest containing the LV cavity in all 12 images was manually defined. For each image, the cavity volume was determined by applying a threshold of $50 \%$ of the maximum value inside that volume of interest.

Anesthetized rats also underwent cMRI with a 9.4-T $20-\mathrm{cm}$ bore horizontal magnet using a linear resonator for excitation combined with a $2 \times 2$-phased array coil for detection (BRUKER Biospin, Ettlingen, Germany) and a retrospectively gated FLASH sequence (INTRAGATE ${ }^{\circledR}$, BRUKER; repetition time (TR)/echo time $(\mathrm{TE})=7.6 / 1.8$ ms, flip angle $=17^{\circ}$, matrix $=256 \times 256$, field of view $(\mathrm{FOV})=6 \times 6 \mathrm{~cm}, 10$ to 121 -mm-thick short axis slices covering the LV, 15 frames reconstructed). To ensure stable and reproducible results, physiological parameters such as body temperature and respiratory and heart rates were carefully monitored throughout the imaging session, and it is noteworthy to mention that there was an interval of 7 to 10 days between the micro-PET and cMRI scan. A manual delineation of the endocardium, ignoring the papillary muscles, was carried out using a homemade software for cMRI [19]. The LVEF values were computed as follows: $\mathrm{LVEF}=(\mathrm{EDV}-\mathrm{ESV} / \mathrm{EDV}) \times 100$, where $\mathrm{EDV}$ and ESV are end-diastolic volume and end-systolic volumes, respectively.

\section{Pig study}

Myocardial infarction was induced in $25-$ to $30-\mathrm{kg}$ domestic pigs as previously described [20]. In brief, the left anterior descending coronary artery was temporarily occluded by a 90-min balloon inflation of a bare metal stent distal to the first diagonal branch. Continuous 
ECG and invasive pressure monitoring was registered during the whole procedure. Eight weeks later, gated blood pool PET and MRI were performed. $\left[{ }^{18} \mathrm{~F}\right]-(5)$ $(185 \mathrm{MBq})$ was administered via a venous catheter, and a 60-min ECG-gated PET scan was acquired in the list mode (HiRez Biograph 16, Siemens, Knoxville, TN, USA). A low-dose CT scan was conducted for attenuation correction. Based on the simultaneously recorded ECG signal, the cardiac cycle was divided in eight frames, and a PET sinogram was created from the list mode data for each frame. From these sinograms, eight images were reconstructed using 2D OSEM (five iterations and eight subsets) after Fourier rebinning. LV volumes and EF were determined in the same way as for the small animal study, i.e., by applying a threshold of $50 \%$ of the maximum in a manually defined volume of interest containing the cavity. The person who analyzed the PET data was blinded from the MRI results.

The MRI images were obtained in supine position on a 3-T unit (TRIO, Siemens, Erlangen, Germany) with ECG gating and during suspended respiration. A contiguous stack of short-axis images covering the entire ventricle was acquired with a 2D FLASH (fast low-angle shot) sequence using retrospective gating and the following imaging parameters: TR/TE $=25.45 / 2.39 \mathrm{~ms}$, flip angle $=14^{\circ}$, matrix $=170 \times 208, \mathrm{FOV}=310 \times 380 \mathrm{~mm}$, slice thickness $=6 \mathrm{~mm}, 40$ cardiac phases, bandwidth $445 \mathrm{~Hz} /$ pixel). Volumes were determined by manual contouring in the same manner as described for the rat studies above.

All animal studies were approved by the Ethics Committee for Animal Experimentation (KU Leuven, Belgium) and were performed in accordance with the Guide for Care and Use of Laboratory Animals (NIH).

\section{Results and discussion \\ Results \\ Chemistry and radiochemistry}

The $O$-acetyl protected intermediate (1) was obtained by treatment of 4-acetoxybenzoylchloride with 4-(2-aminoethyl-benzene)sulfonamide (AEBS) as described by Kuhnast et al. [21]. Hydrolysis of the acetyl protecting group resulted in the phenolic precursor (2) with a chemical yield of $80 \%$. Alkylation of precursor (2) with 1-bromo2-fluoro-ethane or 1-bromo-2-[ $\left[{ }^{18} \mathrm{~F}\right]$ fluoroethane $\left({ }^{18} \mathrm{FEtBr}\right)$ resulted in the reference compound (3) and the radiolabeled fluoroethoxy derivative $\left[{ }^{18} \mathrm{~F}\right]-(3)$, respectively. The ${ }^{11} \mathrm{C}$-labeled methoxyderivative $\left[{ }^{11} \mathrm{C}\right]-(4)$ was obtained similarly by alkylation of (2) with ${ }^{11} \mathrm{CH}_{3} \mathrm{I}$ (Figure 1), and the reference compound (4) was synthesized by acylation of AEBS with 4-methoxybenzoyl chloride. Similarly, the other small (radiolabeled) sulfonamide derivatives, $\left[{ }^{18} \mathrm{~F}\right]-(5)$ and $\left[{ }^{11} \mathrm{C}\right]-(\mathbf{6})$, were obtained by alkylation of commercially available 4-hydroxybenzene-1-sulfonamide (HBS) with ${ }^{18} \mathrm{FEtBr}$ and ${ }^{11} \mathrm{CH}_{3} \mathrm{I}$, respectively. The reference compound of (5) has been synthesized similarly by alkylation of HBS with 1-bromo-2-fluoroethane (Figure 2). The authentic reference material $(\mathbf{6})$ for $\left[{ }^{11} \mathrm{C}\right]-(\mathbf{6})$ was obtained commercially. All tracers were obtained with good radiochemical yield of $30 \%$ to $65 \%$ and high radiochemical purity $(\geq 98 \%)$. The identity of the radiotracers was confirmed by coelution with authentic reference compounds.

\section{$\log D_{p H}{ }_{7.4}, P S A$, and $K_{i}$}

Table 1 summarizes $\log \mathrm{D}$, polar surface area (PSA), and the in vitro $K_{\mathrm{i}}$ data of reference compounds, along with AAZ.

\section{Whole blood analysis}

The human whole blood analysis revealed that all four studied tracers had a rapid uptake, and $\geq 90 \%$ of the

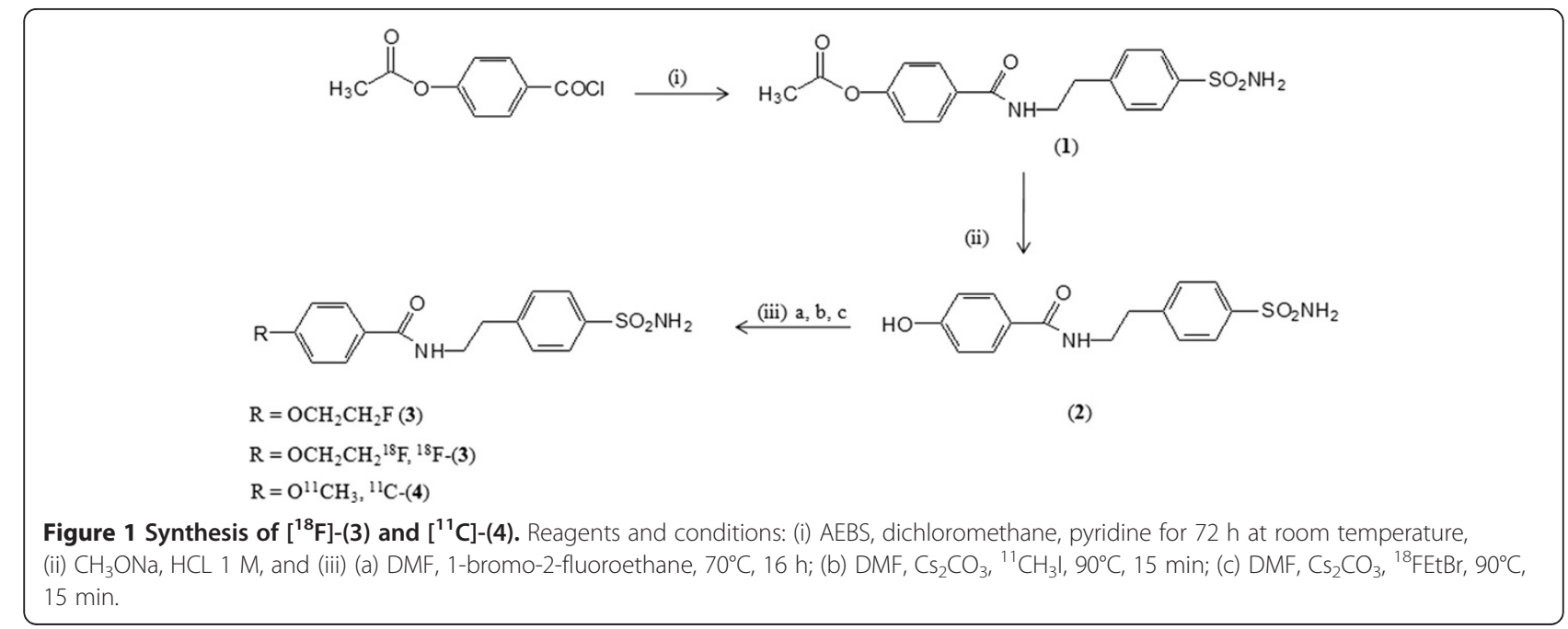



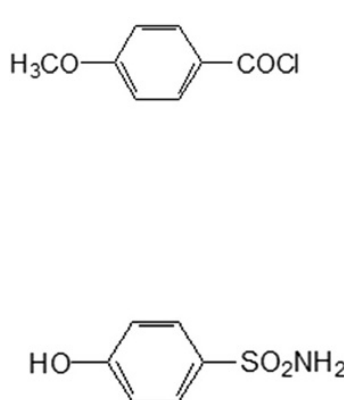

$\stackrel{\text { (i) } \mathrm{a}, \mathrm{b}, \mathrm{c}}{\longrightarrow}$

(b)

(a)

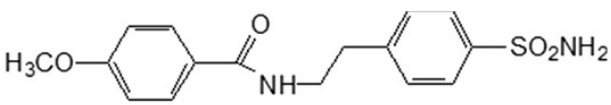

(4)

Figure 2 Synthesis of $\left[{ }^{18} \mathrm{~F}\right]-(\mathbf{5})$ and $\left[{ }^{11} \mathrm{C}\right]-(\mathbf{6})$. Reagents and conditions: (a) (i) AEBS, dichloromethane, pyridine for $72 \mathrm{~h}$ at room temperature. (b) (i) (a) DMF, 1-bromo-2-fluoroethane, $70^{\circ} \mathrm{C}, 16 \mathrm{~h}$; (b) DMF, NaOH $1 \mathrm{M},{ }^{11} \mathrm{CH}_{3} \mathrm{l}, 90^{\circ} \mathrm{C}, 15 \mathrm{~min}$; (c) $\mathrm{DMF}, \mathrm{NaOH} 1 \mathrm{M},{ }^{18} \mathrm{FEtBr}, 90^{\circ} \mathrm{C}, 15 \mathrm{~min}$.

radioactivity was found in the RBCs after a 10 - and 60min incubation at RT. Furthermore, the radiotracer binding to carbonic anhydrases in RBCs was demonstrated from competitive inhibition studies by incubating the whole blood samples with radiotracers in the presence of the CA nonspecific inhibitor, AAZ, with final concentrations ranging from $10 \mu \mathrm{M}$ to $1 \mathrm{mM}$. Figure 3 shows a sigmoid dose response curve with a reduction in the uptake of tracer (three- to eightfold) at concentrations ranging from 200 to $500 \mu \mathrm{M}$ of AAZ, indicating a competitive binding of AAZ to CA I/II which is in agreement with an earlier report [22].

\section{Distribution of activity within blood}

The activity incubated with the blood was distributed in the RBC-rich sediment $(92.5 \pm 1.8 \%)$, and only $7.0 \pm$ $1.6 \%$ and $0.5 \pm 0.2 \%$ were found in the plasma-rich supernatant and WBC-rich compartment, respectively.

\section{Biodistribution studies}

Biodistribution studies in mice (Table 2) demonstrated a high blood pool retention of about $\geq 69 \%$ ID at 2 min p.i. and $\geq 52 \%$ ID at $60 \mathrm{~min}$ p.i. for all tracers, except in the case of $\left[{ }^{18} \mathrm{~F}\right]-(3)$ where only $32 \%$ ID at $60 \mathrm{~min}$ p.i. was

Table $1 K_{\mathrm{i}}$ of reference compounds (3 to 6) against carbonic anhydrase isozymes hCA I and II

\begin{tabular}{lcccc}
\hline Compound & \multicolumn{2}{c}{$\boldsymbol{K}_{\mathbf{i}}(\mathbf{n M})^{\mathbf{a}}$} & Log D & CPSA $^{\mathbf{d}}\left(\AA^{\mathbf{2}}\right)$ \\
\cline { 2 - 5 } & $\mathbf{h C A ~ ~ ^ { \mathbf { b } }}$ & $\mathbf{h C A ~ \mathbf { I } ^ { \mathbf { b } }}$ & & \\
\hline$(\mathbf{3})$ & 96 & 8 & 1.13 & 99 \\
$(\mathbf{4})$ & 390 & 20 & 1.19 & 99 \\
$(\mathbf{5})$ & 30,850 & 336 & 0.32 & 69 \\
$(\mathbf{6})$ & 24,700 & 422 & 0.42 & 69 \\
AAZ & 250 & 12 & $-1.5^{c}$ & 109 \\
\hline
\end{tabular}

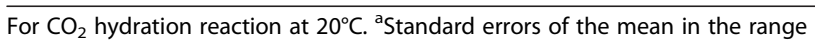
of $5 \%$ to $10 \%$ of the reported value ( $n=3$, different assays); b human (cloned) isozymes; ${ }^{c} \mathrm{CLog} \mathrm{D} ;{ }^{\mathrm{d}} \mathrm{CPSA}=$ (calculated) polar surface area. observed. All the other organs (the lungs, heart, brain, spleen, and pancreas) showed minimal tracer retention at $60 \mathrm{~min}$ p.i. The clearance of tracers $\left[{ }^{18} \mathrm{~F}\right]-(3)$ and $\left[{ }^{18} \mathrm{~F}\right]-(5)$ was mainly through the renal pathway $(\geq 15 \%$ ID in urine at $60 \mathrm{~min}$ p.i.), whereas for $\left[{ }^{11} \mathrm{C}\right]-(4)$ and $\left[{ }^{11} \mathrm{C}\right]-(\mathbf{6})$, the clearance was mainly via the hepatobiliary pathway (12\% to $19 \%$ ID in the intestines at $60 \mathrm{~min}$ p.i.). In the carcass, about $16 \%$ to $29 \%$ ID was observed at 2 and 60 min p.i. for all tracer agents; this is probably due to the activity associated with the residual blood in the carcass.

\section{Small animal imaging studies}

In view of the biodistribution results and the longer half-life of fluorine-18 (110 $\mathrm{min})$ compared with carbon-11 (20 min), further imaging studies were performed with $\left[{ }^{18} \mathrm{~F}\right]-(5)$. A proof-of-concept in vivo visualization of blood pool activity was carried out by acquiring a 1-h dynamic micro-PET scan in rats. The PET data revealed a high blood pool activity in the heart and excellent visualization of all major blood vessels with minimal leakage of tracer to the extravascular compartment (Figure 4).

The time activity curves in rats (Figure 5) show that large blood pool organs such as the liver, spleen, and kidneys had a lower tracer uptake and retention compared with the heart (SUV of 2.5). The average SUV ratios of heart-to-spleen, heart-to-liver, and heart-tokidney were found to be $2.3,4$, and 2.5 respectively, with an excellent target-to-background activity ratio. The LVEF values with micro-PET for rats 1 and 2 were found to be $75 \%$ and $61 \%$ at rest and under pharmacological stress $84 \%$ and $85 \%$, respectively. Similarly, using cMRI, the LVEF values were found to be $53 \%$ and $73 \%$ at rest and under pharmacological stress $81 \%$ and $82 \%$, respectively (Figure 6). 


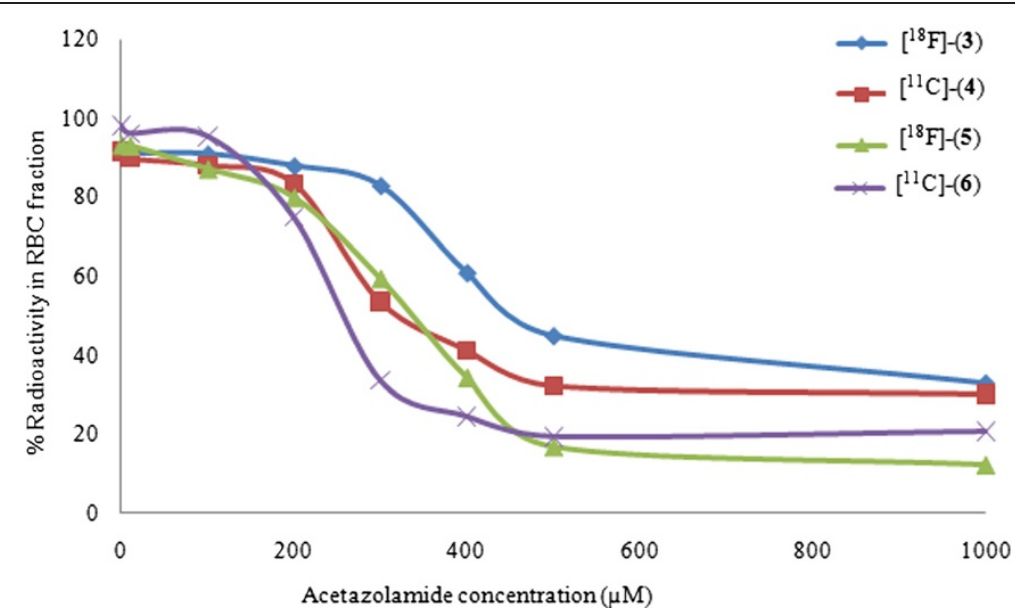

Figure 3 Uptake of $\left[{ }^{18} \mathrm{~F}\right]-(3),\left[{ }^{11} \mathrm{C}\right]-(4),\left[{ }^{18} \mathrm{~F}\right]-(5)$, and $\left[{ }^{11} \mathrm{C}\right]-(6)$ in human $\mathrm{RBC}$ versus AAZ concentration. Data are expressed as percentage of radioactivity in the cell fractions.

\section{Pig study}

Whole body imaging obtained 60 min after tracer injection reveals high activity in the left and right atria and ventricles, in the spleen, and in all major blood vessels (Figure 7a).

Similar to small animal studies, quantitative evaluation of LV volumes and EF with PET shows a good agreement with values obtained by cMRI (Figure $7 \mathrm{~b}$ ).

\section{Discussion}

The aim of this study was to develop PET tracers for in vivo labeling of RBCs and to evaluate their potential application for assessing cardiac function. CA isozyme II, an efficient catalyst involved in the physiological reaction of reversible hydration of carbon dioxide to bicarbonate and a proton, is abundantly present in the RBCs

Table 2 Biodistribution of $\left[{ }^{18} \mathrm{~F}\right]-(3),\left[{ }^{11} \mathrm{C}\right]-(4),\left[{ }^{18} \mathrm{~F}\right]-(5)$, and $\left[{ }^{11} \mathrm{C}\right]-(6)$ in normal NMRI mice

\begin{tabular}{|c|c|c|c|c|c|c|c|c|c|}
\hline \multicolumn{2}{|l|}{ Organs } & \multicolumn{2}{|c|}{$\left[{ }^{18} \mathrm{~F}\right]-(3)$} & \multicolumn{2}{|c|}{$\left[{ }^{11} \mathrm{C}\right]-(4)$} & \multicolumn{2}{|c|}{$\left[{ }^{18} \mathrm{~F}\right]-(5)$} & \multicolumn{2}{|c|}{$\left[{ }^{11} \mathrm{C}\right]-(6)$} \\
\hline & & $2 \min$ & $60 \mathrm{~min}$ & $2 \min$ & $60 \mathrm{~min}$ & $2 \min$ & $60 \mathrm{~min}$ & $2 \min$ & $60 \mathrm{~min}$ \\
\hline \multirow[t]{11}{*}{ Percentage of ID } & Urine & $0.2 \pm 0.1$ & $15.9 \pm 6.0$ & $0.4 \pm 0.1$ & $4.4 \pm 2.7$ & $0.3 \pm 0.1$ & $10.0 \pm 5.0$ & $0.3 \pm 0.1$ & $4.8 \pm 0.3$ \\
\hline & Kidneys & $10.6 \pm 0.8$ & $2.8 \pm 0.1$ & $8.1 \pm 1.3$ & $4.1 \pm 0.3$ & $4.1 \pm 0.8$ & $3.7 \pm 1.1$ & $3.7 \pm 0.1$ & $4.1 \pm 0.6$ \\
\hline & Liver & $15.8 \pm 1.5$ & $8.3 \pm 1.2$ & $8.4 \pm 0.7$ & $9.2 \pm 1.1$ & $6.0 \pm 1.1$ & $4.0 \pm 0.2$ & $6.9 \pm 0.4$ & $6.1 \pm 0.5$ \\
\hline & Spleen + pancreas & $1.3 \pm 0.2$ & $0.9 \pm 0.3$ & $0.6 \pm 0.1$ & $0.8 \pm 0.1$ & $1.1 \pm 0.1$ & $0.9 \pm 0.4$ & $1.2 \pm 0.1$ & $2.3 \pm 0.6$ \\
\hline & Lungs & $2.3 \pm 0.5$ & $0.7 \pm 0.3$ & $4.9 \pm 2.5$ & $4.2 \pm 1.1$ & $7.3 \pm 3.9$ & $1.8 \pm 0.6$ & $6.3 \pm 2.7$ & $3.1 \pm 1.4$ \\
\hline & Heart & $0.8 \pm 0.0$ & $0.2 \pm 0.2$ & $0.5 \pm 0.1$ & $0.5 \pm 0.1$ & $0.6 \pm 0.1$ & $0.6 \pm 0.2$ & $0.7 \pm 0.2$ & $0.4 \pm 0.1$ \\
\hline & Intestines & $5.9 \pm 0.8$ & $18.6 \pm 1.0$ & $3.6 \pm 1.3$ & $12.4 \pm 0.8$ & $2.9 \pm 0.4$ & $9.6 \pm 2.8$ & $5.2 \pm 0.9$ & $19.3 \pm 1.0$ \\
\hline & Stomach & $0.7 \pm 0.1$ & $1.9 \pm 1.3$ & $0.7 \pm 0.1$ & $2.6 \pm 0.3$ & $0.8 \pm 0.2$ & $4.2 \pm 3.1$ & $1.5 \pm 0.3$ & $2.4 \pm 0.2$ \\
\hline & Brain & $0.2 \pm 0.0$ & $0.2 \pm 0.1$ & $0.2 \pm 0.0$ & $0.3 \pm 0.0$ & $0.3 \pm 0.0$ & $1.0 \pm 0.1$ & $0.7 \pm 0.1$ & $1.5 \pm 0.1$ \\
\hline & Blood & $71.0 \pm 4.3$ & $31.7 \pm 2.1$ & $90.5 \pm 5.9$ & $72.5 \pm 7.6$ & $106.3 \pm 5.2$ & $71.0 \pm 14.5$ & $83.4 \pm 7.7$ & $49.7 \pm 4.8$ \\
\hline & Carcass & $18.10 \pm 2.32$ & $31.35 \pm 3.67$ & $17.6 \pm 1.5$ & $21.2 \pm 2.8$ & $18.8 \pm 1.6$ & $22.4 \pm 1.5$ & $28.4 \pm 2.0$ & $26.1 \pm 1.0$ \\
\hline \multirow[t]{7}{*}{ SUV } & Kidneys & $5.6 \pm 0.6$ & $1.6 \pm 0.1$ & $4.3 \pm 0.7$ & $2.5 \pm 0.2$ & $3.1 \pm 0.6$ & $2.5 \pm 0.4$ & $2.4 \pm 0.3$ & $2.4 \pm 0.2$ \\
\hline & Liver & $3.2 \pm 0.2$ & $1.7 \pm 0.3$ & $1.5 \pm 0.2$ & $1.9 \pm 0.3$ & $1.4 \pm 0.3$ & $1.0 \pm 0.1$ & $1.5 \pm 0.1$ & $1.4 \pm 0.2$ \\
\hline & Spleen & $1.6 \pm 0.2$ & $1.1 \pm 0.3$ & $0.9 \pm 0.1$ & $1.1 \pm 0.2$ & $2.1 \pm 0.7$ & $2.2 \pm 0.8$ & $1.9 \pm 0.8$ & $2.4 \pm 0.4$ \\
\hline & Lungs & $3.5 \pm 1.0$ & $1.1 \pm 0.4$ & $6.0 \pm 1.6$ & $4.7 \pm 0.7$ & $9.3 \pm 2.9$ & $3.8 \pm 0.4$ & $6.2 \pm 2.1$ & $3.5 \pm 1.1$ \\
\hline & Heart & $2.3 \pm 1.3$ & $0.5 \pm 0.4$ & $1.2 \pm 0.2$ & $1.0 \pm 0.3$ & $1.6 \pm 0.4$ & $1.7 \pm 0.5$ & $1.6 \pm 0.4$ & $0.9 \pm 0.1$ \\
\hline & Brain & $0.2 \pm 0.0$ & $0.1 \pm 0.0$ & $0.2 \pm 0.0$ & $0.2 \pm 0.0$ & $0.5 \pm 0.1$ & $1.4 \pm 0.2$ & $0.7 \pm 0.1$ & $1.1 \pm 0.1$ \\
\hline & Blood & $10.1 \pm 0.6$ & $4.5 \pm 0.3$ & $12.9 \pm 0.8$ & $10.4 \pm 1.1$ & $17.3 \pm 2.5$ & $11.1 \pm 1.2$ & $11.9 \pm 1.1$ & $7.1 \pm 0.7$ \\
\hline
\end{tabular}

This activity is at 2 and 60 min p.i. Data are expressed as mean \pm standard error $(n=3)$. 


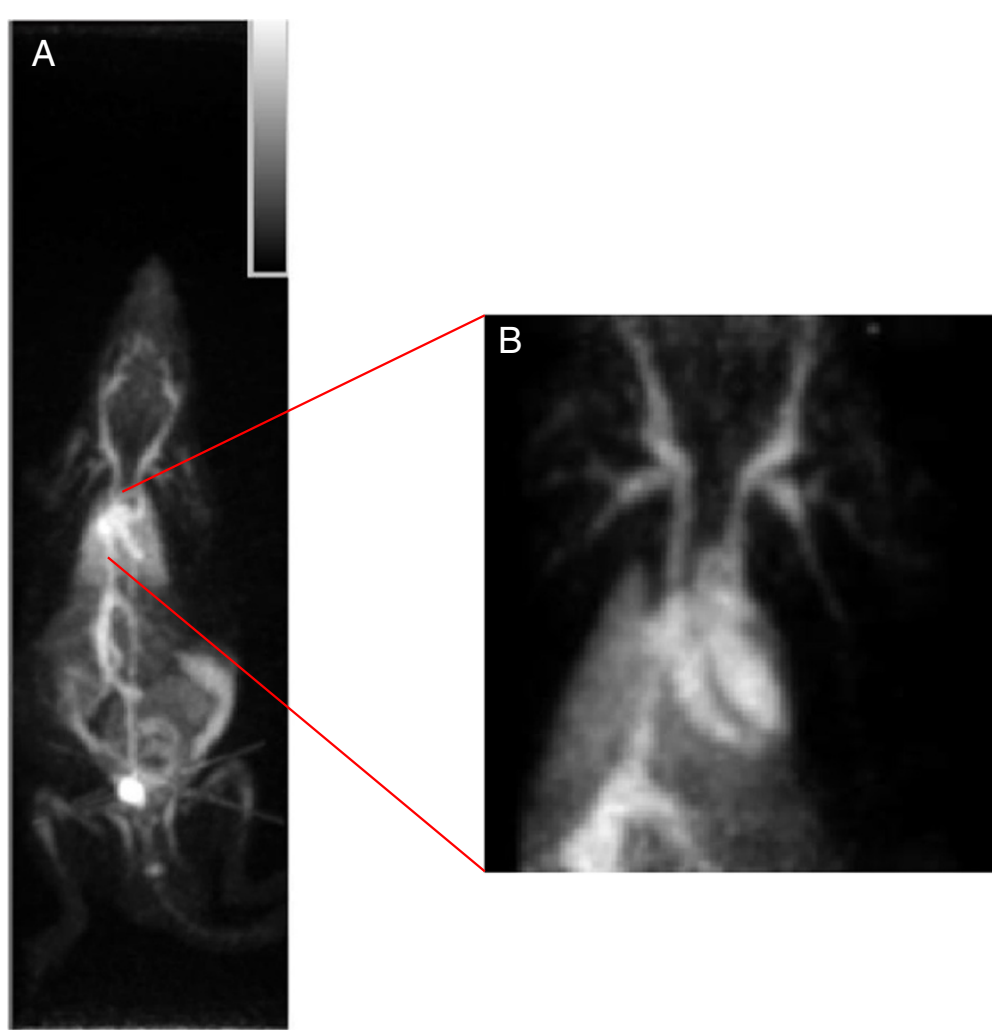

Figure 4 Maximum intensity projection images. (A) Maximum intensity projection micro-PET image after administration of $37 \mathrm{MBq}$ of $\left[{ }^{18} \mathrm{~F}\right]-(\mathbf{5})$, showing high activity in the heart and large blood vessels. (B) Maximum intensity projection detail of the heart showing high activity in the left and right ventricles of the heart and in all of the major blood vessels.

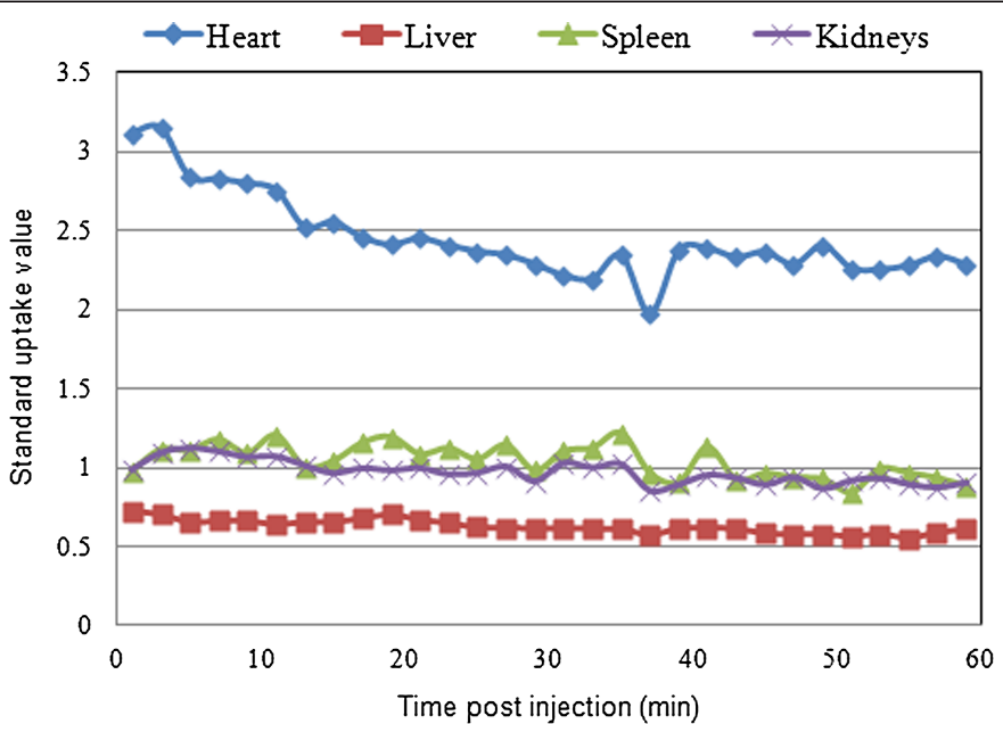

Figure 5 Time activity curves of $\left[{ }^{18} \mathrm{~F}\right]-(5)$ in various organs versus myocardial blood pool activity. Time activity curves of $\left[{ }^{18} \mathrm{~F}\right]-(\mathbf{5})$ in the liver, spleen, and kidneys of a Wistar rat in comparison with the myocardial blood pool activity illustrating good retention of tracer in the blood pool compartment with excellent target-to-background ratios. 


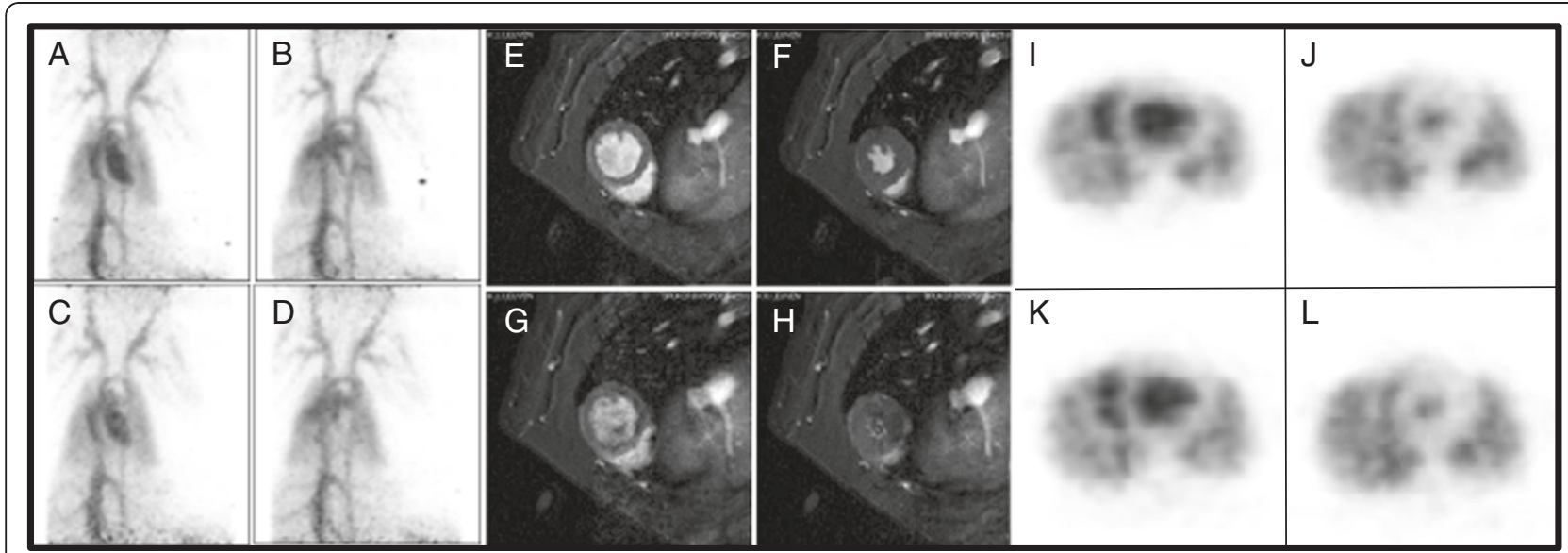

Figure 6 Retrospective ECG-gated micro-PET and CMRI images of a representative rat. (A, E, I) End-diastolic and (B, F, J) end-systolic frames during rest on micro-PET and CMRI, respectively. $(\mathbf{C}, \mathbf{G}, \mathbf{K})$ End-diastolic and $(\mathbf{D}, \mathbf{H}, \mathbf{L})$ end-systolic images during pharmacological stress in the same rat. The lower ESV in stress condition is clearly observed on both micro-PET and CMRI. (left panel: PET maximum intensity projection images, central panel: axial MRI images, right panel: axial PET images).

(17 to $20 \mu \mathrm{M})$ and can be functionally inhibited by sulfonamide derivatives [23]. Several highly specific and potent inhibitors targeting CA II were reported in the literature [24]. Here, we synthesized ${ }^{11} \mathrm{C}$ and ${ }^{18} \mathrm{~F}$ sulfonamide derivatives in a straightforward reaction with good radiochemical yield and purity. To penetrate the cellular membrane and to interact with CA II localized in the cytosol, the tracer agents need to be lipophilic and have a PSA $<90 \AA^{2}[25,26]$. The calculated PSA was found to be $69 \AA^{2}$ for $\left[{ }^{18} \mathrm{~F}\right]-(5)$ and $\left[{ }^{11} \mathrm{C}\right]-(6)$. Due to the additional amide bond, the cPSA value increased to $99 \AA^{2}$ for $\left[{ }^{18} \mathrm{~F}\right]-(3)$ and $\left[{ }^{11} \mathrm{C}\right]-(\mathbf{4})$. In order to be efficient tracers for in vivo labeling of erythrocytes, it is critical that the tracer agents rapidly diffuse in the RBC where they bind to CA I/II isozymes after intravenous injection. The fraction of the tracer which is not bound to the RBCs should be minimal at the time that the injection bolus reaches organs such as the liver or kidneys to avoid clearance through these excretory organs. It is thus anticipated that the labeling efficiency will be higher in larger species as not only a larger excess of CA I/II is available, but also the relative cardiac output is lower and the

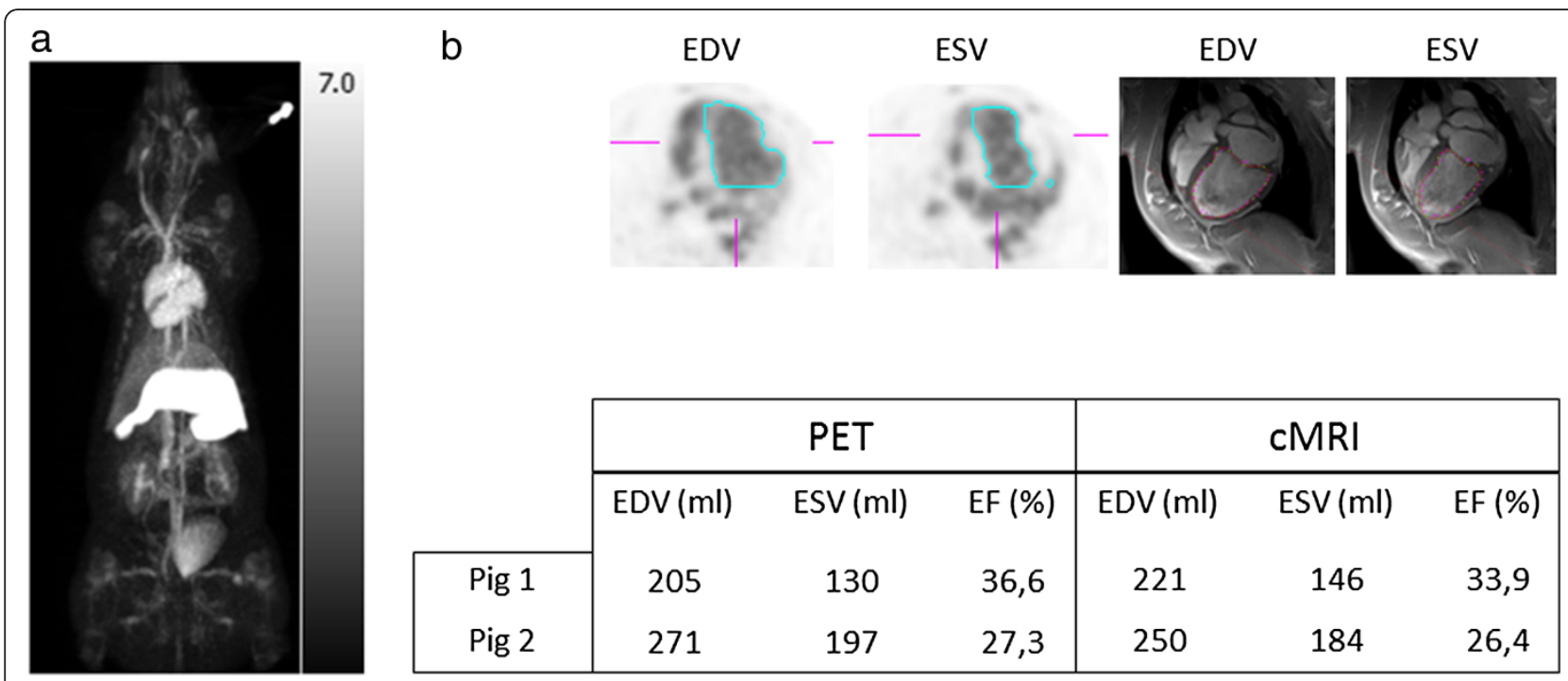

Figure 7 Coronal maximum intensity projection of the pig model and quantitative evaluation with PET and MRI. (a) Coronal maximum intensity projection of the pig model reveals high activity in the left and right atria and ventricles, in the spleen, and in all major blood vessels. (b) Representative image illustrating delineation of ESV and EDV on PET and CMRI. A good agreement was observed between PET and MRI for quantification of LV volumes and EF. 
circulation time is slower. This is in accordance with the much slower blood clearance in man versus rats for the radioiodinate sulfonamides reported by Singh et al. [14].

The data of Table 1 show that the investigated compounds demonstrated lower inhibition constants for CA II and higher CA II vs. CA I specificity of compounds (3) and (4) versus compounds (5) and (6). Human whole blood analysis indicated that the tracer agents were retained $\geq 90 \%$ in RBCs at 10 and 60 min post incubation at room temperature, suggesting their membranepermeable nature. Further experiments showed that more than $90 \%$ of the activity is confined to the RBCs and not to other constituents of the blood. In addition, the competition study with CA inhibitor AAZ indicates that the binding to RBCs is due to specific interaction with CA I/II. Biodistribution studies in mice showed significant accumulation of all tested tracer agents in the blood pool at 2 min with a relative decrease of $23 \%$ to $53 \%$ of the blood pool-associated activity at 60 minutes p.i. Compound $\left[{ }^{18} \mathrm{~F}\right]-(3)$ shows only $32 \%$ ID at $60 \mathrm{~min}$ p.i. in the blood in contrast with its potent inhibitory activity against CA II $\left(K_{\mathrm{i}}=8 \mathrm{nM}\right)$ and its PSA value which is comparable to that of $\left[{ }^{11} \mathrm{C}\right]-(\mathbf{4})$ for which the blood retention at $60 \mathrm{~min}$ p.i. was twice as high (68\%). The higher urinary excretion of ${ }^{18} \mathrm{~F}$-labeled compounds compared to their carbon-11 analogs may be caused by urinary excretion of polar radiometabolites which may not be generated in the case of the ${ }^{11} \mathrm{C}$-labeled compounds.

The potential application to calculate LVEF values in rats and pigs was demonstrated in a proof-of-concept study with $\left[{ }^{18} \mathrm{~F}\right]-(5)$. As shown in Figure 5, the highest SUV in rats was observed over the heart region for which the SUV value at $60 \mathrm{~min}$ amounted to $75 \%$ of the 2 -min value. Furthermore, it is noteworthy that no bone uptake was observed, indicating the absence of in vivo defluorination. The presence of free fluoride would have an adverse effect with high background activity in the upper skeleton and would result in inaccurate quantification due to partial volume effects. The potential application of the tracer for assessing cardiac function was demonstrated by measuring the global parameters ( $\mathrm{LV}$ volumes and $\mathrm{EF}$ ) in rest and stress conditions using ECG micro-PET and cMRI. In stress condition, there was a good correlation of LVEF values between PET and cMRI. In rest condition, the obtained LVEF values were somewhat more variable for both techniques. This discrepancy can be attributed to subtle changes in the physiology of the animal even though every effort was made to obtain comparable study conditions, e.g., using a common anesthesia protocol.

In the pig model of myocardial infarction, an excellent agreement was found between the EF and LV values obtained with MRI and PET, respectively. The whole body image (Figure 7a) largely reflects blood pool with high activity in the heart and major blood vessels. In contrast to the human spleen, the pig's spleen stores about $20 \%$ of its total number of RBCs which explains the high activity observed in this organ [27]. A small amount of activity was also observed in the bladder.

In view of the low extravascular activity in the abdomen, this tracer can potentially be used for PET visualization of gastrointestinal bleeding and hemangioma with higher resolution and sensitivity compared with SPECT using technetium-labeled erythrocytes. Labeling of the RBCs with $\left[{ }^{18} \mathrm{~F}\right]-(5)$ has the advantage that it can potentially be used for any species, and in addition, it does not require any manipulation of blood.

Both PET and cMRI endure certain limitations, especially in terms of manual delineation of ESV and EDV, which is subjected to a risk of partial volume effect on PET, and for CMRI, there is a risk for misdelineation of contours at the myocardium. Nevertheless, the study demonstrated the ability of the synthesized PET tracers to allow assessment of LVEF and volumes in rats and pigs. As mentioned above, a slower clearance from the blood pool compartment of these tracers in humans compared with rats and pigs is anticipated so that further clinical evaluation of this compound is warranted.

\section{Conclusions}

Our results clearly demonstrate that the developed ${ }^{11} \mathrm{C}$ or ${ }^{18} \mathrm{~F}$-labeled sulfonamide derivatives can be used for blood pool imaging using PET. Our initial in vitro and in vivo evaluation indicates the tracer's ability to efficiently radiolabel RBCs in vivo. Biodistribution and imaging studies revealed mainly blood pool activity with minimal background signal. In a proof-of-concept study, we demonstrated the applicability of ECG-gated PET to assess cardiac function and volumes in rats and in a pig model of myocardial infarction. Further studies are warranted to fully exploit the potential of this tracer and translate it to clinical applications.

\section{Additional file}

Additional file 1: Reference analogs (1-5) and production of the secondary radiolabeling agents ${ }^{11} \mathrm{CH}_{3} \mathrm{l}$ and ${ }^{18} \mathrm{FEtBr}$.

\section{Competing interests}

The authors declare that they have no competing interests.

\section{Authors' contributions}

Each author has contributed significantly to the submitted work: OG designed the study, carried out the PET imaging studies, analyzed the data, and wrote the manuscript. VA, SC, BJC, and RC carried out the (radio) synthesis, in vitro evaluation, and biodistribution studies, and VA co-wrote the work. TD and UH carried out and analyzed the micro-MRI studies, MK carried out the PET experiments, DD carried out the pig studies, and PC carried out and analyzed the pig MRI studies. JN, AMV, SJ, and GMB were responsible for the design and critical revision of the manuscript. All authors read and approved the final manuscript. 


\section{Acknowledgments}

We thank Prof. Claudiau Supuran and Dr. Alessio Innocenti (Department of Chemistry, University of Florence, Italy) for providing the $K_{i}$ data. We also thank Peter Vermaelen and Ann Van Santvoort (MoSAIC, K.U. Leuven, Belgium) for their excellent technical assistance. This work is supported by In vivo Molecular Imaging Research (IMIR), K.U. Leuven, Belgium. Olivier Gheysens holds a senior clinical investigator fellowship, and Dieter Dauwe holds a predoctoral fellowship from the FWO-Flanders.

\section{Author details}

${ }^{1}$ Nuclear Medicine, University Hospital Leuven, Herestraat 49, Leuven BE-3000, Belgium. '2Department of Imaging and Pathology, Katholieke Universiteit Leuven, Herestraat 49, Leuven BE-3000, Belgium. ${ }^{3}$ Laboratory of Radiopharmacy, Katholieke Universiteit Leuven, O\&N2, Herestraat 49, Box 821, Leuven BE-3000, Belgium. ${ }^{4}$ Biomedical NMR Unit, Katholieke Universiteit Leuven, O\&N2, Herestraat 49, Leuven BE-3000, Belgium. ${ }^{5}$ Cardiovascular Diseases, University Hospital Leuven, Herestraat 49, Leuven BE-3000, Belgium. ${ }^{6}$ Division of Cardiology, Department of Cardiovascular Sciences, Katholieke Universiteit Leuven, Herestraat 49, Leuven BE-3000, Belgium. ${ }^{7}$ Division of Imaging and Cardiovascular Dynamics, Department of Cardiovascular Sciences, Katholieke Universiteit Leuven, Herestraat 49, Leuven BE-3000, Belgium.

Received: 7 September 2012 Accepted: 2 January 2013

Published: 15 January 2013

\section{References}

1. Kalyani MS: Cardiac blood pool tracers. J Nucl Med 1991, 32:480-481.

2. Davey RJ: The uses of radiolabeled red cells in transfusion medicine. Transfus Med Rev 1988, 2:151-160.

3. Eckelman W, Richards P, Hauser W, Atkins H: Technetium-labeled red blood cells. J Nucl Med 1971, 12:22-24.

4. Levy R, Barto W, Gani J: Retrospective study of the utility of nuclear scintigraphic-labelled red cell scanning for lower gastrointestinal bleeding. ANZ J Surg 2003, 73:205-209.

5. Front D, Israel O, Groshar D, Weininger J: Technetium-99m-labeled red blood cell imaging. Semin Nucl Med 1984, 14:226-250.

6. Welch M, Thakur M, Coleman R, Patel M, Siegel B, Ter-Pogossian M: Gallium-GB labeled red cells and platelets: new agents for positron tomography. J NuCl Med 1977, 8:558-562.

7. Cross SJ, Lee HS, Metcalfe MJ, Norton MY, Evans NT, Walton S: Assessment of left ventricular regional wall motion with blood pool tomography: comparison of ${ }^{11}$ CO PET with ${ }^{99 m}$ TC SPECT. Nucl Med Commun 1994, 15:283-288.

8. Subramanyam R, Alpert NM, Hoop B, Hoop B Jr, Brownell GL, Taveras JM: A model for regional cerebral oxygen distribution during continuous inhalation of $\mathrm{C}^{15} \mathrm{O}_{2}, \mathrm{C}^{15} \mathrm{O}$, and ${ }^{11} \mathrm{CO}_{2}$. J NuCl Med 1978, 19:48-53.

9. Okazawa $H$, Yamauchi $H$, Sugimoto $K$, Toyoda $H$, Kishibe $Y$, Takahashi M: Effects of acetazolamide on cerebral blood flow, blood volume, and oxygen metabolism: a positron emission tomography study with healthy volunteers. J Cereb Blood Flow Metab 2001, 21:1472-1479.

10. Sorensen J, Velikyan I, Antoni G, Langstrom B: ${ }^{68} \mathrm{Ga}$-labeled Human Serum Albumin. Patent no: WO/2011/033112, 24 March 2011.

11. Mathias CJ, Welch MJ, Green MA, Diril H, Meares CF, Gropler RJ, Bergmann SR: In vivo comparison of copper blood-pool agents: potential radiopharmaceuticals for use with copper-62. J Nucl Med 1991, 32:475-480.

12. Hoffend J, Mier W, Schuhmacher J, Schmidt K, Dimitrakopoulou-Strauss A, Strauss LG, Eisenhut M, Kinscherf R, Haberkorn U: Gallium-68-DOTAalbumin as a PET blood-pool marker: experimental evaluation in vivo. Nucl Med Biol 2005, 32:287-292.

13. Singh J, Wyeth $P$ : The enzyme-inhibitor approach to cell-selective labeling - I. Sulphonamide inhibitors of carbonic anhydrase as carriers for red cell labeling: in vitro uptake of pIBS by human red blood cells. Int J Rad Appl Instrum A 1991, 42:251-259.

14. Singh J, Wyeth P, Ackery DM, Zivanovic MA: The enzyme-inhibitor approach to cell selective labeling - II. In vivo studies with pIBS in small animals and man. Int J Rad Appl Instrum A 1991, 42:261-267.

15. Vanbilloen HP, Kieffer DM, Cleynhens BJ, Bormans GM, Mortelmans L, Verbruggen AM: Evaluation of ${ }^{99 m}$ Tc-labeled tropanes with alkyl substituents on the $3 \beta$-phenyl ring as potential dopamine transporter tracers. Nucl Med Biol 2006, 334:13-18.

16. Khalifah RG: The carbon dioxide hydration activity of carbonic anhydrase I. Stop-flow kinetic studies on the native human isoenzymes B and C. J Biol Chem 1971, 246:2561-2573.

17. Mortelmans L, Malbrain S, Stuyck J, De Backker C, Heynen MJ, Boogaerts M De Roo M, Verbruggen A: In vitro and in vivo evaluation of granulocyte labeling with [ $\left.{ }^{99 \mathrm{~m}} \mathrm{Tc}\right] \mathrm{d}, 1-\mathrm{HM}-\mathrm{PAO}$. J Nucl Med 1989, 30:2022-2028.

18. Hoff J: Methods of blood collection in the mouse. Lab Anim 2000, 29:47-53.

19. Wu M, D'hooghe J, Ganame J, Ferferieva V, Sipido K, Maes F, Dymarkowski $S$, Bogaert J, Rademakers F, Claus P: Non-invasive characterization of the area-at-risk using magnetic resonance imaging in chronic ischaemia. Cardiovasc Res 2011, 89:166-174.

20. Liu X, Huang $Y$, Pokreisz $P$, Vermeersch P, Marsboom G, Swinnen M, Verbeken E, Santos J, Pellens M, Gillijns H, Van de Werf F: Nitric oxide inhalation improves microvascular flow and decreases infarction size after myocardial ischemia and reperfusion. JAAC 2007, 50:808-817.

21. Kuhnast B, Bodenstein C, Wester HJ, Weber W: Carbon-11 labeling of an N-sulfonylamino acid derivative: a potential tracer for MMP-2 and MMP-9 imaging. J Label Compd Radiopharm 2003, 46:539-553.

22. Zandvliet AS, Copalu W, Schellens JH, Beijnen JH, Huitema AD: Saturable binding of indisulam to plasma proteins and distribution to human erythrocytes. Drug Metab Dispos 2006, 34:1041-1046.

23. Supuran CT: Carbonic anhydrases: novel therapeutic applications for inhibitors and activators. Nat Rev Drug Discov 2008, 7:168-181.

24. Supuran CT: Structure-based drug discovery of carbonic anhydrase inhibitors. J Enzyme Inhib Med Chem 2012, 27(6):759-772.

25. Ertl P, Rohde B, Selzer P: Fast calculation of molecular polar surface area directly from SMILES. http://www.daylight.com/meetings/emug00/Ertl/index. html.

26. Chaturvedi PR, Decker CJ, Odinecs A: Prediction of pharmacokinetic properties using experimental approaches during early drug discovery. Curr Opin Chem Biol 2001, 5:452-463.

27. Hannon JP, Bossone CA, Rodkey WG: Splenic red cell sequestration and blood volume measurements in conscious pigs. Am J Physiol 1985, 248:R293-R301.

doi:10.1186/2191-219X-3-4

Cite this article as: Gheysens et al:: Preclinical evaluation of carbon-11 and fluorine-18 sulfonamide derivatives for in vivo radiolabeling of erythrocytes. EJNMMI Research 2013 3:4.

\section{Submit your manuscript to a SpringerOpen ${ }^{\odot}$ journal and benefit from:}

- Convenient online submission

- Rigorous peer review

- Immediate publication on acceptance

- Open access: articles freely available online

- High visibility within the field

- Retaining the copyright to your article

Submit your next manuscript at $>$ springeropen.com 